\title{
Desempenho produtivo de genótipos de alface crespa no Submédio do Vale do São Francisco
}

Agronomical performance of crispleaf lettuce genotypes at Sub-Middle São Francisco Valley

\author{
Resende, G. A. ${ }^{*}$; Yuri, J. E. ${ }^{1}$; Costa, N. D. ${ }^{2}$; Gomes, A. S. ${ }^{1}$; Mota, J. H. ${ }^{3}$ \\ ${ }^{1 *}$ Embrapa Semiárido, Rodovia BR-428, Km 152, s/n, Zona Rural, CEP 56302-970, Petrolina- PE, Brasil \\ ${ }^{2}$ Universidade de Pernambuco, Rodovia BR 203, Km 2, s/n, Vila Eduardo, CEP 56328-903, Petrolina, PE, Brasil \\ ${ }^{3}$ Universidade Federal de Goiás-Regional Jataí, Rodovia BR 364, Km 192, Setor Parque Industrial \\ CEP 75801-615, Jataí, GO, Brasil \\ *geraldo.milanez@embrapa.br
}

(Recebido em 03 de maio de 2017; aceito em 10 de outubro de 2017)

\begin{abstract}
A alface crespa é entre os diversos tipos cultivados no país a mais importante. O presente trabalho objetivou avaliar o desempenho produtivo de genótipos de alface crespa no Submédio do Vale do São Francisco. O delineamento experimental utilizado foi de blocos ao acaso com quatro repetições. Avaliaram-se seis genótipos de alface (Amanda, Bruna, Vanda, Isabela, CAP/CR/77-1 e 10Y3104-1) em duas épocas de plantio (inverno e verão). Os genótipos Vanda (400 g planta ${ }^{-1}$ e 49,3 $\mathrm{t} \mathrm{ha}^{-1}$ ) e CAP/CR/77-1 (383 g planta ${ }^{-1}$ e 48,0 t $\mathrm{ha}^{-1}$ ) obtiveram os melhores desempenhos para massa fresca e produtividade na época de inverno. Para o cultivo na época de verão sobressaíram os genótipos 10Y3104-1 (281 $\mathrm{g} \mathrm{planta}^{-1}$ e 34,6 t ha $\left.{ }^{-1}\right)$, CAP/CR/77-1 (280 g planta ${ }^{-1}$ e 34,5 t ha $\left.{ }^{-1}\right)$ e Vanda $\left(272 \mathrm{~g} \mathrm{planta}^{-1}\right.$ e 33,6 tha $\left.\mathrm{ga}^{-1}\right)$. O número de folhas variou entre 26,3 e 30,1 folhas planta ${ }^{-1}$ para genótipos, sendo o maior valor constatado no inverno $\left(27,4\right.$ folhas planta $\left.{ }^{-1}\right)$ comparativamente ao verão $\left(25,8\right.$ folhas planta $\left.{ }^{-1}\right)$. Para comprimento do caule os genótipos apresentaram variação entre $7,2 \mathrm{~cm}$ e $9,6 \mathrm{~cm}$, com maiores valores no verão $(9,0 \mathrm{~cm})$ em relação ao inverno $(7,3 \mathrm{~cm})$. Apenas os genótipos Bruna e Amanda apresentaram por ocasião da colheita incidência de pendoamento precoce, em condições de temperaturas mais elevadas (verão).

Palavras-chave: Lactuca sativa, rendimento, competição de cultivares, adaptação, época de plantio
\end{abstract}

Crispleaf lettuce is among the many types grown in the most important country. This study aimed to evaluate the behavior of cultivars of crispleaf lettuce at Sub-Middle São Francisco Valley. It was used a randomized complete block design with four replications. Six genotypes of lettuce (Amanda, Bruna, Vanda, Isabela, CAP / CR / 77-1 and 10Y3104-1) were evaluated in two planting seasons (winter and summer). The genotypes Vanda (400 g plant ${ }^{-1}$ and $\left.49.3 \mathrm{t} \mathrm{ha}^{-1}\right)$ and CAP/CR/ 77-1 (367 g plant ${ }^{-1}$ and $\left.47.9 \mathrm{t} \mathrm{ha}^{-1}\right)$ obtained the best performance for fresh and yield under mild temperatures (winter). For the planting under higher temperatures (summer) showed the genotypes 10Y3104-1(281 g plant ${ }^{-1}$ and $\left.34.6 \mathrm{t} \mathrm{ha}^{-1}\right), \mathrm{CAP} / \mathrm{CR} / 77-1$ (280 g plant ${ }^{-1}$ and $\left.34.5 \mathrm{t} \mathrm{ha}^{-1}\right)$ and Vanda $\left(272 \mathrm{~g} \mathrm{plant}^{-1}\right.$ and $\left.33.6 \mathrm{tha}^{-1}\right)$. The number of leaves varied between 26.3 and 30.1 leaves plant ${ }^{-1}$ for genotypes, the highest value observed in winter (27.4 leaves plant $\left.{ }^{-1}\right)$ compared to summer (25.8 leaves plant ${ }^{-1}$ ). To stem length genotypes showed variation between $7.2 \mathrm{~cm}$ and $9.6 \mathrm{~cm}$, with higher values in summer $(9.0 \mathrm{~cm})$ compared to winter $(7.3 \mathrm{~cm})$. Only the genotypes Bruna and Amanda presented at the harvest incidence of early tillage, under conditions of higher temperatures (summer).

Keywords: Lactuca sativa, yield, competition, adaptation, planting time

\section{INTRODUÇÃO}

A alface (Lactuca sativa) entre as hortaliças folhosas é a que mais se destaca tanto no Brasil como no mundo, sendo consumida na forma crua, e constituindo-se no principal ingrediente sob a forma de saladas $[1,2]$. Cultivada tradicionalmente por pequenos agricultores trata-se de uma cultura de grande importância sob o ponto de vista econômico como social, empregando grande número de pessoas [3].

Há no mercado hoje uma grande quantidade de cultivares de alface, se diferenciando em termos de formatos da cabeça, de diferentes tamanhos e de diversas cores. Ryder (1999) [4] as classifica em função do formato, dimensão das folhas e sua justaposição e na ausência ou formação de cabeça 
em seis tipos de alface: americana (crisphead), aspargo ou caule (stem), crespa (leaf), lisa (butterhead), oleaginosa (oilseed) e romana (cos) com maior consumo do tipo crespa [1,5]. Nos últimos anos a participação da alface crespa tem sobressaído entre os diferentes tipos tendo alcançado 51\% em 2012, da preferência dos consumidores [6].

Pelos dados de produção nacional da cultura em 2006 (estatística mais recente disponível), foram produzidas 576.338 toneladas. Com 37,4\% e 24,9\% São Paulo e Rio de Janeiro, respectivamente, respondem pelas maiores produções nacionais. Entre as hortaliças cultivadas no Brasil a alface tem papel relevante respondendo por aproximadamente $11,7 \%$ da produção (4.908.772 toneladas). Com 55.841 toneladas, o Nordeste brasileiro produz $9,7 \%$ do total de alface, com destaque para os Estados do Ceará e Pernambuco [7]. A produção nacional é baseada nos denominados "cinturões verdes", no entorno ou próximos aos grandes centros consumidores, razão pela quais as pesquisas próximas aos grandes centros são mais do que fundamentais [1].

É uma planta bastante influenciada por condições ambientais, com temperaturas favoráveis (amenas) ao seu crescimento na faixa entre 15,5 e $18,3^{\circ} \mathrm{C}$, podendo suportar temperaturas entre 26,6 e $29,4^{\circ} \mathrm{C}$, sendo mais importante nessas condições que as temperaturas à noite sejam menores (mais baixas) [8]. $\mathrm{Na}$ faixa de 21,1 a $26,6^{\circ} \mathrm{C}$, por períodos maiores ocorre o denominado pendoamento precoce que promove um crescimento anormal do caule prejudicando a qualidade da cabeça comercial. Para a maioria das cultivares de alface a temperatura suportável máxima esta em torno de $30{ }^{\circ} \mathrm{C}$ [9], com oscilação ideal de 4 a $27^{\circ} \mathrm{C}$ [10]. Para todas as cultivares a ocorrência de temperaturas mais baixas promove um melhor desenvolvimento vegetativo. No Verão não se tem um bom crescimento devido ao efeito da temperatura, fotoperiodo maior e chuvas em excesso, favorecendo a floração precoce e prejudicando a qualidade comercial (folha leitosa e amarga) [11]. Nessa época a recomendação de cultivares mais tolerantes ao calor permite o plantio ao longo do ano [12].

Para o Submédio do Vale do São Francisco o inverno ocorre de abril a setembro e o verão de outubro a março [13]. Nesse contexto é de se esperar que a alface deva se desenvolver e produzir melhor em períodos de temperadas mais baixas (inverno) comparado ao verão (temperaturas em elevação). A temperatura média do ar varia de 24,0 a $28,0{ }^{\circ} \mathrm{C}$, com as temperaturas máxima e mínima oscilando entre 29,6 a $34,0{ }^{\circ} \mathrm{C}$ e de 18,2 a $22,1{ }^{\circ} \mathrm{C}$, respectivamente [13].

Estudos realizados por Gualberto et al. (2009) [14] com plantios no outono, inverno e primavera demonstraram melhor desempenho produtivo e maior massa fresca de cabeça para as cultivares Deyse e Verônica nas diferentes épocas, tendo as demais cultivares apresentado instabilidade com grande oscilação na produtividade evidenciando a necessidade de se estudar a adaptação dessas sob condições locais de plantio.

Santos et al. (2009) [15] observaram para massa fresca de alface tipo crespa oscilação entre 52,5 a $111,5 \mathrm{~g}_{\text {planta }}{ }^{-1}$ e comprimento do caule entre 5,2 e $24,8 \mathrm{~cm}$, em cultivo de verão até $35,3{ }^{\circ} \mathrm{C}$. Em condições de inverno, Ledo et al. (2000) [16] verificaram massa fresca variando entre $192 \mathrm{e} 373 \mathrm{~g}$ planta $^{-1}$, com produtividades comerciais entre 25,5 e 49,8 tha $^{-1}$ e comprimento do caule entre 6,0 a 23,1 cm. Enquanto, Queiroz et al. (2014) [17] relatam variações de massa fresca entre 193,5 (cultivar Isabela) e 301,1 g planta- $^{-1}$ (cultivar Verônica).

Em alface o comprimento do caule pode ser usado como indicador da adaptação das cultivares sob condições de calor, onde menores comprimentos implicam em cultivares melhor adaptadas ao calor e vice-versa [24]. Temperaturas mais elevadas antecipam a fase reprodutiva promovendo a floração das plantas invertendo a fase vegetativa de maior importância na cultura o que torna as folhas impróprias para consumo, em função do látex produzindo que torna as folhas com sabor amargo [30,31]. O comprimento de caule tem papel importante na comercialização da alface, pois está estreitamente relacionado com sua qualidade.

A produção de alface no Brasil se faz no entorno das grandes cidades "cinturões verdes" e nesse contexto justifica-se a necessidade de se avaliar cultivares em condições locais às quais serão plantadas quanto a sua melhor adaptação, rendimento comercial e qualidade do produto final [18]. O presente trabalho objetivou avaliar o desempenho produtivo de genótipos de alface crespa no Submédio do Vale do São Francisco. 


\section{MATERIAL E MÉTODOS}

Foram realizados dois ensaios no Campo Experimental de Bebedouro, Petrolina-PE $\left(9^{\circ} 9^{\prime} \mathrm{S}\right.$, $40^{\circ} 29^{\prime \prime} \mathrm{W}, 365,5 \mathrm{~m}$ de altitude), em Latossolo Vermelho Amarelo Distróferrico [20]. O primeiro ensaio foi conduzido no período de maio a julho de 2014 (inverno), e o segundo no período de setembro a novembro de 2014 (verão). A classificação e as características climáticas da região são descritas por Azevedo et al. (2006) [19]. Os dados climatológicos encontram na nos períodos de execução do experimento no campo encontram-se na Tabela 1.

Tabela 1. Valores mensais de precipitação pluviométrica acumulada, temperaturas máxima, mínima e média e umidade relativa do ar média durante a execução dos experimentos em campo. Petrolina - PE, 2014.

\begin{tabular}{|c|c|c|c|c|c|}
\hline \multirow{2}{*}{ Mês } & \multirow{2}{*}{$\begin{array}{l}\text { Precipitação } \\
\text { (mm) }\end{array}$} & \multicolumn{3}{|c|}{ Temperatura $\left({ }^{\circ} \mathrm{C}\right)$} & \multirow{2}{*}{$\begin{array}{c}\text { Umidade relativa } \\
\qquad(\%)\end{array}$} \\
\hline & & Máxima & Mínima & Média & \\
\hline \multicolumn{6}{|c|}{ Inverno } \\
\hline Maio & 0,0 & 30,3 & 19,9 & 23,7 & 60,0 \\
\hline Junho & 6,0 & 30,5 & 19,0 & 24,6 & 60,7 \\
\hline Julho & 4,0 & 30,0 & 18,4 & 24,1 & 58,8 \\
\hline Média & - & 30,3 & 19,1 & 24,1 & 59,8 \\
\hline \multicolumn{6}{|c|}{ Verão } \\
\hline Setembro & 0,0 & 35,4 & 21,0 & 28,1 & 46,3 \\
\hline Outubro & 1,0 & 34,7 & 21,9 & 27,8 & 73,9 \\
\hline Novembro & 23,0 & 34,0 & 21,1 & 27,5 & 76,0 \\
\hline Média & - & 34,7 & 21,3 & 27,8 & 65,2 \\
\hline
\end{tabular}

Em ambos os ensaios utilizaram-se o delineamento de blocos ao acaso com seis genótipos avaliados (Amanda, Bruna, Vanda, Isabela, CAP/CR/77-1 e 10Y3104-1) e quatro repetições.

As semeaduras foram realizadas em 21/05/2014, no primeiro ensaio e em 24/09/2014, no segundo. Utilizaram-se bandejas de isopor com 288 células e substrato comercial Plantmax, sendo as mudas produzidas em viveiro. Com idade de 28 dias as mudas foram transplantadas para 0 campo. O preparo do solo, feito da mesma forma nos dois ensaios, constou de uma aração, seguida de gradagem e confecção dos canteiros a altura de $0,20 \mathrm{~m}$.

As unidades experimentais foram compostas de canteiros com quatro linhas de 2,0 m de comprimento no espaçamento de $0,25 \times 0,25 \mathrm{~m}\left(2,0 \mathrm{~m}^{2}\right)$, sendo consideradas como área útil as duas linhas centrais $\left(0,75 \mathrm{~m}^{2}\right)$, dispensando uma planta em cada extremidade.

A adubação baseou-se na análise do solo nos dois ensaios e constou de 6,3 $\mathrm{kg} \mathrm{ha}^{-1}$ de $\mathrm{N}$ e 21,3 $\mathrm{kg}$ de $\mathrm{P}_{2} \mathrm{O}_{5}$ ha $^{-1}$ no plantio. Em adubação de cobertura, foram adicionados $38 \mathrm{~kg} \mathrm{ha}^{-1} \mathrm{de} \mathrm{N} \mathrm{e} 26,0 \mathrm{~kg}$ $\mathrm{ha}^{-1}$ de $\mathrm{Ca}$, parcelados em duas vezes ao longo do ciclo, sendo $40 \%$ da quantidade total dos dois nutrientes aos 15 dias e $60 \%$ restantes aos 30 dias após o transplantio. Como fontes de nutrientes foram utilizadas o superfosfato simples, uréia e nitrocálcio.

As irrigações foram feitas através do método de microaspersão, com turno de dois dias e lâminas de água em torno de 9-10 mm (inverno) e 11-12 mm (verão), calculada em função da evaporação do tanque classe A.

As colheitas foram realizadas aos 39 dias e 33 dias após o transplante, respectivamente para o cultivo de inverno e verão, quando as plantas apresentaram-se completamente desenvolvidas. Foram avaliadas a massa fresca $\left(\mathrm{g}_{\text {planta }}{ }^{-1}\right)$; produtividade $\left(\mathrm{t} \mathrm{ha}^{-1}\right)$ (retirando $30 \mathrm{~cm}$ de corredores entre canteiros, expressa em área útil de plantio), número de folhas planta ${ }^{-1}$, comprimento e largura das folhas $(\mathrm{cm})$, comprimento do caule $(\mathrm{cm})$ e pendoamento precoce $(\%)$ na colheita. Os dados coletados foram submetidos à análise de variância, utilizando-se o teste $\mathrm{F}$ para comparação dos quadrados médios a 5\% de probabilidade e as médias foram comparadas pelo teste de Scott-Knott, a 5\% de probabilidade, empregando-se o programa SISVAR 5.0 [21]. 


\section{RESULTADOS E DISCUSSÃO}

$\mathrm{Na}$ avaliação de inverno as maiores produções de massa fresca por planta e produtividade foram obtidas pelos genótipos Vanda (400 g planta ${ }^{-1}$ e 49,3 $\mathrm{t} \mathrm{ha}^{-1}$ ) e CAP/CR/77-1 (383 g planta-1 e 48,0 t $\mathrm{ha}^{-1}$ ) (Tabela 2, Figura 1). Em condições de inverno, Ledo et al. (2000) [16] obtiveram massa fresca máxima de $373 \mathrm{~g}$ planta $^{-1}\left(49,8 \mathrm{t} \mathrm{ha}^{-1}\right)$, enquanto, Queiroz et al. (2014) [17] 301,1 g planta-1 e Lima et al. (2004) [22] 33,2 $\mathrm{tha}^{-1}$.

Tabela 2. Massa fresca por planta, comprimento do caule, comprimento, largura e número de folhas de cultivares de alface crespa em cultivo de inverno. Petrolina - PE, 2014.

\begin{tabular}{|c|c|c|c|c|c|}
\hline \multirow{2}{*}{ Cultivares } & \multirow{2}{*}{$\begin{array}{c}\text { Massa fresca } \\
\left(\text { g planta }^{-1}\right)\end{array}$} & \multirow{2}{*}{$\begin{array}{l}\text { Comprimento } \\
\text { do Caule } \\
\text { (cm) }\end{array}$} & \multicolumn{2}{|c|}{ Folhas (cm) } & \multirow{2}{*}{$\begin{array}{c}\text { Número } \\
\text { de } \\
\text { folhas }\end{array}$} \\
\hline & & & Comprimento & Largura & \\
\hline Vanda & $400 \mathrm{a}$ & $9,0 \mathrm{a}$ & $23,4 \mathrm{~b}$ & $18,8 \mathrm{a}$ & $29,7 \mathrm{a}$ \\
\hline CAP/CR/77-1 & $383 \mathrm{a}$ & $6,4 \mathrm{c}$ & $24,7 \mathrm{a}$ & 18,8 a & $27,1 \mathrm{a}$ \\
\hline Bruna & $363 \mathrm{~b}$ & $8,2 \mathrm{a}$ & $25,1 \mathrm{a}$ & 18,9 a & $30,1 \mathrm{a}$ \\
\hline Amanda & $343 \mathrm{~b}$ & $7,6 \mathrm{~b}$ & $23,1 \mathrm{~b}$ & $19,4 \mathrm{a}$ & 26,9 a \\
\hline 10Y3104-1 & $320 \mathrm{c}$ & $6,8 \mathrm{c}$ & $23,0 \mathrm{~b}$ & $17,8 \mathrm{~b}$ & $25,2 \mathrm{a}$ \\
\hline Isabela & $271 d$ & $6,0 \mathrm{c}$ & $21,0 \mathrm{c}$ & $17,6 \mathrm{~b}$ & $26,3 \mathrm{a}$ \\
\hline CV. (\%) & 8,2 & 5,2 & 10,6 & 4,2 & 4,5 \\
\hline
\end{tabular}

* Médias seguidas da mesma letra minúscula na coluna e maiúscula na linha não diferem entre si pelos testes de Scott-Knott e F, respectivamente, a $5 \%$ de probabilidade.

No verão os genótipos 10Y3104-1 (281 g planta $\left.\mathrm{g}^{-1} \mathrm{e} 34,6 \mathrm{t} \mathrm{ha}^{-1}\right), \mathrm{CAP} / \mathrm{CR} / 77-1$ (280 g planta ${ }^{-1} \mathrm{e}$ 34,5 t ha ${ }^{-1}$ ) e Vanda (272 g planta $^{-1}$ e 33,6 $\mathrm{t} \mathrm{ha}^{-1}$ ) sobressaíram-se aos demais (Tabela 3, Figura 1). A produção de massa fresca média por planta no inverno (347 $\mathrm{g} \mathrm{planta}^{-1}$ e $\left.42,8 \mathrm{t} \mathrm{ha}^{-1}\right)$ foi superior à obtida no verão $\left(255 \mathrm{~g} \mathrm{planta}^{-1}\right.$ e $\left.31,7 \mathrm{t} \mathrm{ha}^{-1}\right)$, ou seja, houve redução na produtividade de $26 \%$ no cultivo de verão quando comparado ao inverno. Feltrim et al. (2009) [23] verificaram redução de $40 \%$ na produção de massa fresca no cultivo de verão quando comparado ao de inverno, bem superior aos 26\% encontrados no presente trabalho. Queiroz et al. (2014) [17] também observaram maiores produtividades no inverno comparativamente ao verão, corroborando a afirmação de ser essa época menos adequada ao cultivo da alface.

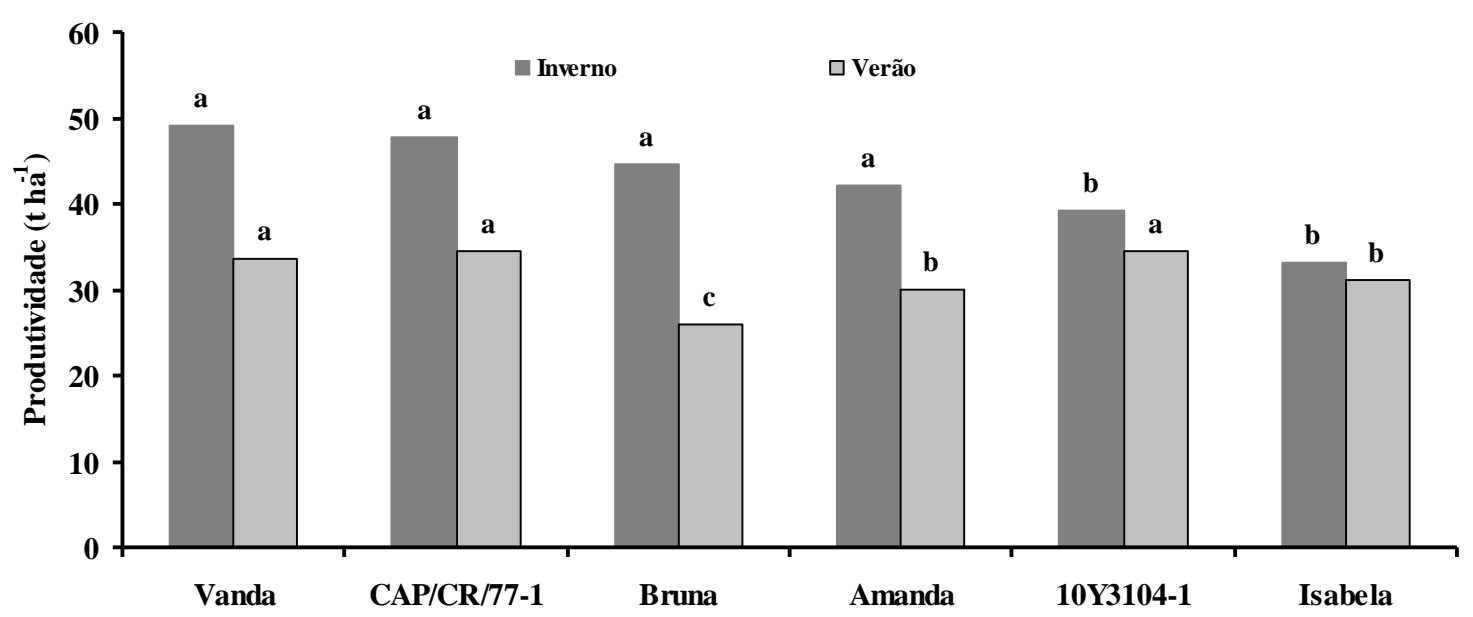

Figura 1. Produtividade de cultivares de alface crespa em cultivo de inverno e verão. Médias seguidas pela mesma letra não diferem entre si, pelo teste de Scott-Knott ( $p \leq 0.05$ C.V. $=8,5$ (inverno) e 3,4\%(verão)). 
A genética de cada cultivar associada ao ambiente de produção influencia as respostas fisiológicas e morfológicas das plantas promovendo diferentes rendimentos das cultivares [24]. Salientando Echer et al., (2001) [25], que a seleção da cultivar é primordial no alcance do sucesso do sistema de cultivo a ser realizado. Segundo Filgueira (2008) [11] e Oliveira et al. (2004) [26] por ser uma espécie que melhor se adaptada a temperaturas mais amenas, se desenvolve e produz melhor sob essas condições, enquanto Feltrim et al. (2009) [23] comparando o plantio de inverno com o verão, verificaram que as plantas produzem menos massa seca na parte aérea na época mais quente devido ao estresse promovido pelas temperaturas mais elevadas.

A cultura que se desenvolve melhor sob temperaturas mais baixas (amenas), com faixa ideal entre de desenvolvimento entre 15,5 e $18,3^{\circ} \mathrm{C}$, tolerando temperaturas entre 26,6 a $29,4^{\circ} \mathrm{C}$ [8]. Em média na execução do trabalho no cultivo de inverno foram obtidas temperatura média de $24,1^{\circ} \mathrm{C}$, com mínima em $19,1^{\circ} \mathrm{C}$ e máxima de $30,3^{\circ} \mathrm{C}$, umidade relativa de $59,8 \%$ e $10 \mathrm{~mm}$ de precipitação acumulada no período (Tabela 1). As temperaturas ocorridas no inverno (temperaturas amenas) foram bem inferiores as do verão (temperaturas mais elevadas) e apesar de não serem as condições ideais para o cultivo da alface, não se mostraram limitantes no cultivo, apresentando maiores massas frescas por planta e produtividades nessa época. Assim como os rendimentos no verão apesar de inferiores não chegaram a inviabilizar o cultivo sob estas condições.

$\mathrm{Na}$ cultura a massa fresca associada ao número de folhas por planta é determinante na produtividade da alface e as características produtivas mais indicadas para selecionar cultivares melhor adaptadas a um local de cultivo juntamente com a preferência do mercado consumidor [26]. A adaptação de uma cultivar pode ser verificada pelo maior número de folhas que esta apresenta, sendo de relevante importância tanto para o produtor como para sua comercialização. Para genótipos encontraram-se variações no inverno entre 25,2 e 29,7 folhas planta ${ }^{-1}$ e no verão entre 23,0 e 30,3 folhas planta ${ }^{-1}$, nos quais destacaram-se os genótipos Bruna (30,3), CAP/CR/77-1 (28,4) e Vanda $(27,1)$ com maior número (Tabelas 2 e 3 ).

Tabela 3. Massa fresca por planta, comprimento do caule, comprimento, largura e número de folhas de cultivares de alface crespa em cultivo de verão. Petrolina - PE, 2014.

\begin{tabular}{|c|c|c|c|c|c|}
\hline \multirow{2}{*}{ Cultivares } & \multirow{2}{*}{$\begin{array}{c}\text { Massa fresca } \\
\left.\text { (g planta }^{-1}\right)\end{array}$} & \multirow{2}{*}{$\begin{array}{c}\text { Comprimento } \\
\text { do Caule } \\
(\mathrm{cm})\end{array}$} & \multicolumn{2}{|c|}{ Folhas (cm) } & \multirow{2}{*}{$\begin{array}{c}\text { Número } \\
\text { de } \\
\text { folhas }\end{array}$} \\
\hline & & & Comprimento & Largura & \\
\hline Vanda & $272 \mathrm{a}$ & $10,2 \mathrm{a}$ & $18,7 \mathrm{~b}$ & $16,2 \mathrm{~b}$ & $27,1 \mathrm{c}$ \\
\hline CAP/CR/77-1 & $280 \mathrm{a}$ & $8,2 \mathrm{~b}$ & $22,5 \mathrm{a}$ & $17,6 \mathrm{a}$ & $28,4 \mathrm{~b}$ \\
\hline Bruna & $212 c$ & $9,2 \mathrm{a}$ & $18,6 \mathrm{~b}$ & $16,0 \mathrm{~b}$ & $30,3 \mathrm{a}$ \\
\hline Amanda & $244 \mathrm{~b}$ & $10,4 \mathrm{a}$ & $18,9 \mathrm{~b}$ & $16,6 \mathrm{~b}$ & $26,1 \mathrm{~d}$ \\
\hline 10Y3104-1 & $281 \mathrm{a}$ & $8,8 \mathrm{~b}$ & $19,7 \mathrm{~b}$ & $16,6 \mathrm{~b}$ & $23,0 \mathrm{e}$ \\
\hline Isabela & $243 \mathrm{~b}$ & $6,6 \mathrm{c}$ & $17,6 \mathrm{c}$ & $16,2 \mathrm{~b}$ & $26,1 \mathrm{~d}$ \\
\hline CV. (\%) & 4,5 & 6,3 & 2,9 & 6,9 & 2,5 \\
\hline
\end{tabular}

* Médias seguidas da mesma letra minúscula na coluna e maiúscula na linha não diferem entre si pelos testes de Scott-Knott e F, respectivamente, a 5\% de probabilidade

Valores similares foram constatados por Blat et al. (2011) [27] que obtiveram números de folhas entre 22,3 a 30,2 folhas por planta. Feltrim et al. (2009) [23] obtiveram para as cultivares Vera e Verônica 29,5 folhas, no inverno e verão, em cultivo no solo e hidropônico. Enquanto Santos et al. (2011) [28] obtiveram valores pouco inferiores para as melhores cultivares com variações entre 23,0 e 25,1 folhas.

Não foram observadas diferenças significativas os genótipos CAP/CR/77-1 $(24,7 \mathrm{~cm})$ e Bruna $(25,1 \mathrm{~cm})$ para comprimento da folha no plantio de inverno (Tabela 2). Destacou-se no verão o genótipo CAP/CR/77-1 $(22,5 \mathrm{~cm})$. A média de comprimento das folhas no inverno $(23,4 \mathrm{~cm})$ foi superior ao do verão $(19,3 \mathrm{~cm})$. Para largura de folhas (Tabela 2) verificou-se uma amplitude relativamente pequena entre os genótipos no inverno com oscilação entre 17,6 cm ('Isabela') e 19,4 $\mathrm{cm}$ ('Amanda'). No verão a maior largura de folha foi obtida pelo genótipo CAP/CR/77-1 com 17,6 $\mathrm{cm}$ (Tabela 3). A largura média das folhas no inverno $(18,6 \mathrm{~cm})$ foi superior a do verão $(16,5 \mathrm{~cm})$. 
Os genótipos que apresentaram os menores comprimentos de caule no inverno e verão foram Isabela, CAP/CR/77-1 e 10Y3104-1 (Tabela 2 e 3). Em termos médios o plantio de verão apresentou em 9,0 cm de comprimento do caule, resultado bem superior aos 7,3 cm observados para o inverno. Em cultivo de verão, Santos et al. (2009) [15] obtiveram para o mesmo tipo de alface médias entre 5,2 e $24,8 \mathrm{~cm}$, demonstrando que essa variável pode ser influenciada pela genética da cultivar como pelas condições de cultivo locais com menores comprimentos de caule obtidos pela cultivar Vanda com 5,2 cm. Comprimento de caule de diferentes cultivares oscilando entre 6,6 e 10,7 cm em cultivo de inverno são informados por Tosta et al. (2009) [29]. O que se verifica é que comprimentos de caule até $9-10 \mathrm{~cm}$ são passiveis de comercialização, sendo não recomendados acima disso. O tamanho ideal seria de comprimentos de caule entre 5,0 e 6,0 cm. Nesse sentido, todos os genótipos de alface estariam perfeitamente dentro da faixa considerada adequada para serem comercializados.

Não se verificou nenhum índice de pendoamento (florescimento prematuro) entre os genótipos avaliados no inverno por ocasião da colheita demonstrando que os mesmos são bem adaptados para cultivo nessa época. No plantio sob condições de temperaturas mais elevadas do verão, apenas os genótipos Amanda (11,7\%) e Bruna com 13,3\% apresentaram-se com plantas emitindo um pendoamento inicial na colheita, fato esse não verificado para os demais genótipos. Nas condições climáticas em que se conduziu o trabalho com temperatura máxima média entre $30,3{ }^{\circ} \mathrm{C}$ (inverno) e $34,7^{\circ} \mathrm{C}$ (verão) verificou-se que a maior temperatura obtida no período de verão esta pouco acima da temperatura máxima suportada pela cultura que é de $30{ }^{\circ} \mathrm{C}$ para a maioria das cultivares [9] e provavelmente explica a não adaptação dos genótipos Amanda e Bruna a estas condições climáticas. Nessa situação, a colheita precisa ser antecipada, o que resulta em produtos de qualidade inferior e prejuízos para o produtor [32].

\section{CONCLUSÃO}

O genótipo Vanda pode ser cultivado durante todo o ano (verão e inverno) nas condições edafoclimáticas do Submédio do Vale do São Francisco.

No inverno destacam-se os genótipos Vanda, Bruna e Amanda Plus, e no verão 10Y3104-1, Vanda e CAP/CR/77-1.

\section{REFERÊNCIAS BIBLIOGRÁFICAS}

1. Sala FC, Costa CP. Retrospectiva e tendência da alfacicultura brasileira. Horticultura Brasileira. 2012 Abr/Jun;30(2):187-194, doi:http://dx.doi.org/10.1590/S0102-05362012000200002

2. Cometti NN, Matias GCS, Zonta E, Mary W, Fernandes MS. Compostos nitrogenados e açúcares solúveis em tecidos de alface orgânica, hidropônica e convencional. Horticultura Brasileira. 2004 Out/Dez;22(4):748-753, doi:http://dx.doi.org/10.1590/S0102-05362004000400016

3. Villas Bôas RL, Passos JC, Fernandes M, Büll LT, Cezar VRS, Goto R. Efeito de doses e tipos de composto orgânicos na produção de alface em dois solos sob ambiente protegido. Horticultura Brasileira. 2004 Jan/Mar;22(1):28-34, doi:http://dx.doi.org/10.1590/S0102-05362004000100006

4. Ryder EJ. Lettuce, endive and chicory. New York: CABI Publishing; 1999. 208p.

5. Trani PE, Tivelli SW, Purquerio LFV, Azevedo Filho JA. Informações tecnológicas - Alface (Lactuca sativa L.). Campinas: IAC. Disponível em: <http://www.iac.sp.gov.br/infotecnologicas.php> Acesso em: 18 outubro 2016.

6. Gutierrez ASD, Rocha IL. Desempenho da alface na Ceagesp. Jornal Entreposto, 2013;159:6-7.

7. IBGE - Instituto Brasileiro de Geografia e Estatística. Censo Agropecuário de 2006. Disponível em: <www.ibge.gov.br>. Acesso em: 4 maio 2016.

8. Sanders DC. Lettuce production. Disponível em: <http://www.ces.ncsu.edu/hil /hil-11.html> Acesso em: 23 maio 2016.

9. Duarte RLR, Silva PHS, Ribeiro VQ. Avaliação de cultivares de alface nos períodos chuvosos e secos em Terezina-PI. Horticultura Brasileira. 1992 Nov;10(2):106-108.

10. Puiatti M, Finger FL. Fatores climáticos. In: Fontes PCR. (Ed.). Olericultura - teoria e prática. Viçosa: Editora UFV, 1 ed. 2005. p. 17-38.

11. Filgueira FAR. Novo Manual de Olericultura: Agrotecnologia moderna na produção e comercialização de hortaliças. Viçosa: UFV; 2008. 421p. 
12. Lima ME. Avaliação do desempenho da cultura da alface (Lactuca sativa) cultivada em sistema orgânico de produção, sob diferentes lâminas de irrigação e cobertura do solo. [Tese Mestrado] Rio de Janeiro (RJ): Universidade Federal do Rio de Janeiro; 2007. 77p.

13. Teixeira AHC. Informações agrometeorológicas do Pólo Petrolina, PE/Juazeiro - 1963 a 2009. Petrolina: Embrapa Semiárido. 21p. 2010. (Embrapa Semiárido. Documentos, 233).

14. Gualberto R, Oliveira PSR, Guimarães AM. Adaptabilidade e estabilidade fenotípica de cultivares de alface do grupo crespa, em cultivo hidropônico. Horticultura Brasileira. 2009 Jan/Mar;27(1):7-11, doi:http://dx.doi.org/10.1590/S0102-05362009000100002

15. Santos CL, Junior Seabra S, Lalla JG, Theodoro VCA, Nespoli A. Desempenho de cultivares de alface tipo crespa sob altas temperaturas em Cáceres-MT. Agrarian. 2009 Jan/Mar;2(3):87-98.

16. Ledo FJS, Sousa JÁ, Silva MR. Desempenho de cultivares de alface no Estado do Acre. Horticultura Brasileira. 2000 Nov;18(3):225-228, doi:http://dx.doi.org/10.1590/S0102-05362000000300 017

17. Queiroz JPS, Costa AJM, Neves LG, Seabra Júnior S, Barelli MAA. Estabilidade fenotípica de alfaces em diferentes épocas e ambientes de cultivo. Ciência Agronômica. 2014 Abr/Jun;45(2):276-283.

18. Rodrigues IN, Lopes MTG, Lopes R, Gama AS, Milagres CP. Desempenho de cultivares de alface na região de Manaus. Horticultura Brasileira. 2008 Out/Dez;26(4):524-527, doi:http://dx.doi.org/ 10.1590/S0102-05362008000400020

19. Azevedo PV, Sousa IF, Silva BB, Silva VPR. Water-use efficiency of dwarf-green coconut (Cocos nucifera L.) orchards in Northeast Brazil. Agricultural Water Management. 2006 Aug;84(1):259-264, doi:http://dx.doi.org/10.1016/j.agwat.2006.03.001

20. Santos HG, Jacomine PKT, Anjos LHC, Oliveira VA, Oliveira JB, Coelho MR, Lumbreras JF, Cunha TJF. (Eds.) Sistema brasileiro de classificação de solos. 2. ed. Rio de Janeiro: Embrapa Solos; 2006. 306 p.

21. Ferreira DF. Sisvar: A computer statistical analysis system. Ciência e Agrotecnologia. 2011 Nov/Dec;35(6):1039-1042, doi:http://dx.doi.org/10.1590/S1413-70542011000600001

22. Lima AA, Miranda EG, Campos LZO, Cuznato Junior WH, Melo SC, Camargo MSC. Competição das cultivares de alface Vera e Verônica em dois espaçamentos. Horticultura Brasileira. 2004 Abr/Jun;22(2):314-316, doi:http://dx.doi.org/10.1590/S0102-05362004000200030

23. Feltrin AL, Cecílio Filho AB, Rezende BLA, Branco RBF. Produção de alface-crespa em solo e em hidroponia, no inverno e verão, em Jaboticabal-SP. Científica. 2009;37(1):9-15, doi:http:// dx.doi.org/10.15361/1984-5529.2009v37n1p9+-+15

24. Hermes CC, Medeiros SLP, Manfron PA, Caron B, Pommer SF, Bianchi C. Emissão de folhas de alface em função de soma térmica. Revista Brasileira de Agrometeorologia. 2001;9(2): 269-275.

25. Echer MM, Sigrist JMM, Guimarães VF, Minami K. Comportamento de cultivares de alface em função do espaçamento. Revista de Agricultura. 2001;76(2):267-275.

26. Oliveira ACB, Sediyama MAN, Pedrosa MW, Garcia NC, Garcia SLR. Divergência genética e descarte de variáveis em alface cultivada sob sistema hidropônico. Acta Scientiarum: agronomy. 2004;26(2):211217, doi:10.4025/actasciagron.v26i2.1894

27. Blat SF, Sanchez SV, Araújo JAC, Bolonhezi D. Desempenho de cultivares de alface crespa em dois ambientes de cultivo em sistema hidropônico. Horticultura Brasileira. 2011 Jan/Mar;29(1):135-138, doi:http://dx.doi.org/10.1590/S0102-05362011000100024

28. Santos D, Mendonça RMN, Silva SM, Espínola JEF, Souza AP. Produção comercial de cultivares de alface em Bananeiras. Horticultura Brasileira. 2011 Out/Dez;29(4):609-612, doi:http://dx.doi.org/10. 1590/S0102-05362011000400028

29. Tosta MS, Borges FSP, Reis LL, Tosta JS, Mendonça V, Tosta PAF. Avaliação de quatro cultivares de alface para cultivo de outono em Cassilândia-MS. Agropecuária Científica no Semi-Árido. 2009; 5(1):3035.

30. Magalhães AG, Menezes D, Resende LV, Bezerra Neto, E. Desempenho de cultivares de alface em cultivo hidropônico sob dois níveis de condutividade elétrica. Horticultura Brasileira. 2010 Jul/Set;28(3):316-320, doi:http://dx.doi.org/10.1590/S0102-05362010000300013

31. Carvalho Filho JLS, Gomes LAA, Maluf WR. Tolerância ao florescimento precoce e características comerciais de progênies F4 de alface do cruzamento Regina 71 x Salinas 88. Acta Scientiarum. Agronomy. 2009;31(1):37-42, doi:http://dx.doi.org/10.4025/actasciagron.v31i1.6607

32. Whitaker TW, Ryder EJ. Lettuce production in the United States. Washington: USDA; 1974. 218p. 